\title{
The Effect of Indapamide on Development of Myocardial Hypertrophy and Fibrosis in L-NAME-Induced Hypertension in Rat
}

\author{
L. HLAVAČKOVÁ ${ }^{1}$, S. VRANKOVÁ ${ }^{2}$, P. JANEGA ${ }^{1,2}$, O. PECHÁŇOVÁ ${ }^{2}$, P. BABÁL ${ }^{1}$ \\ ${ }^{1}$ Department of Pathology, Faculty of Medicine, Comenius University, Bratislava, Slovak Republic, \\ ${ }^{2}$ Departement of Normal and Pathological Physiology and Centre of Excellence for Cardiovascular \\ Diseases, Slovak Academy of Science, Bratislava, Slovak Republic
}

Received March 27, 2011

Accepted September 16, 2011

On-line October 12, 2011

\section{Summary}

The aim of this study was to analyze the effect of indapamide and its combination with ACE inhibitor (captopril) and antioxidant (Provinols $^{\mathrm{TM}}$ ) on both myocardial hypertrophy and fibrosis. Wistar rats were treated with L-NAME (40 mg/kg/day, L); L-NAME plus indapamide (1 $\mathrm{mg} / \mathrm{kg} /$ day), or captopril $(10 \mathrm{mg} / \mathrm{kg} / \mathrm{day})$, or Provinols ${ }^{\mathrm{TM}}$ (40 mg/kg/day), or combination of indapamide with captopril, and indapamide with Provinols ${ }^{\mathrm{TM}}$ for 7 weeks. Blood pressure (BP), LV hypertrophy and fibrosis were determined. The content of collagens type I and III was evaluated morphometrically after picrosirius red staining. L-NAME treatment led to increased BP, LV hypertrophy, total fibrosis and relative content of collagens without the change in collagen type I/III ratio. Indapamide and captopril decreased BP, LV hypertrophy and the collagen ratio without affecting total fibrosis, while Provinols ${ }^{\mathrm{TM}}$ reduced $\mathrm{BP}$, the collagen ratio and fibrosis without affecting LV hypertrophy. The combinations decreased all the parameters. Decrease of LV hypertrophy was achieved by drugs with the best reducing effect on BP, fibrosis reduction was reached by the antioxidant treatment with only partial effect on BP. Thus, the combination of antihypertensive and antioxidant treatment may represent a powerful tool in preventing myocardial remodeling induced by hypertension.

\section{Key words}

Captopril • Indapamide • LV hypertrophy • Myocardial fibrosis • Red wine polyphenols

\section{Corresponding author}

P. Babál, Department of Pathology, Faculty of Medicine, Comenius University, Sasinkova 4, 81108 Bratislava, Slovak Republic. Fax: +421 259357 592. E-mail: pavel.babal@fmed.uniba.sk

\section{Introduction}

Persistently increased blood pressure is one of the risk factors for various cardiovascular diseases and is associated with left ventricular (LV) hypertrophy (Gottdiener et al. 1997). Increased myocardial mass is determined by enlargement of cardiac myocytes, which may be accompanied by proliferation of fibroblasts and the expansion of extracellular matrix. The collagen accumulation and the left ventricular hypertrophy develop as the consequences of increased blood pressure and both are considered to participate at myocardial stiffening (Narayan et al. 1989, Schraeger et al. 1994).

The effect of NO-synthase inhibitor $N(\mathrm{G})$-nitroL-arginine methyl ester (L-NAME) on left ventricular hypertrophy is disputable. According to some findings, even chronic (6-8 weeks) administration of this NO synthase inhibitor did not cause significant change in the mass of the left ventricle (Arnal et al. 1992, 1993, Bartunek et al. 2000). Some authors observed hypertrophy development not before 8 weeks (Moreno et al. 1996, Takemoto et al. 1997) while others described development of left ventricular hypertrophy after 4 weeks of treatment with L-NAME (Bernátová et al. 1996, 2000, Pechánová et al. 1999). The effect of L-NAME on myocardial fibrosis has been well described by various authors. It seems that accumulation of collagen in the myocardium is not directly connected with increased blood pressure but rather with the decreased NO synthesis that leads to activation of neurohormonal systems and growth-promoting factors (Moreno et al. 1996, Takemoto et al. 1997, Pechánová et al. 1999, 
Bernátová et al. 2000). It is supposed that NO deficiency rather than hemodynamic changes appears to be crucially involved in fibrous tissue changes of the left ventricle in hypertension induced by L-NAME (Pechánová et al. 1999).

Myocardial extracellular matrix is composed of various structural proteins, predominantly of collagens type I and III (Weber 1989). Collagen type I (Col I) provides strength and rigidity, whereas tissues with large amount of collagen type III (Col III) are characterized by increased elasticity (Marijianowski et al. 1995). Recent studies showed that the different collagens accumulation is connected with the development of heart failure, increased passive stiffness and impaired contractile function (Conrad et al. 1995, Yamamoto et al. 2002). Some authors (Mukherjee and Sen 1990) suppose the ratio of collagen type I/III (Col I/III ratio) to be a more important prognostic factor than the total amount of collagens and it was proved that its increase is associated with dilatation cardiomyopathy (Marijianowski et al. 1995) and with post-infarction remodeling of unaffected myocardium of both ventricles (Wei et al. 1999).

Myocardial hypertrophy as well as fibrosis enlargement may be influenced by various therapeutic agents including antihypertensives. Indapamide, a non thiazide diuretic, has been used for its antihypertensive and blood pressure variability stabilizing effect (Zhang et al. 2011). It also was documented to reduce left ventricular hypertrophy and total myocardial fibrosis in stroke prone spontaneously hypertensive rats (SHR) (Contard et al. 1993). According to Janega et al. (2007) the effect of indapamide in SHR was not dependent on nitric oxide production. Indapamide is often combined with other antihypertensive drugs like angiotensineconverting enzyme (ACE) inhibitors. Captopril, an ACE inhibitor with thiol groups, caused regression of left ventricular hypertrophy, significantly changed Col I/III ratio in SHR and was able to decrease the total amount of collagen in the heart after chronic treatment with L-NAME (Mukherjee and Sen 1993, Pechánová et al. 1997). Since antioxidant properties of 5-OH indapamide, the major metabolite of indapamide, have been described (Vergely et al. 1998), it was hypothesized that the possible antihypertophic and/or antifibrotic properties of indapamide might be supported by antioxidants. Red wine polyphenols with powerful antioxidant effect, have been shown to reduce fibrosis development yet without affecting left ventricular hypertrophy caused by L-NAME treatment (Bernátová et al. 2002, Pechánová et al. 2004,
Hlavačková et al. 2009).

The aim of this study was to analyze the effect of indapamide and its combination with captopril or red wine polyphenols $\left(\right.$ Provinols $^{\mathrm{TM}}$ ) on left ventricular hypertrophy and collagen type I and type III content in myocardium in the model of experimental NO deficient hypertension.

\section{Methods}

All procedures and experimental protocols were approved by the Ethical Committee of the Institute of Normal and Pathological Physiology SAS, and conform to the European Convention on Animal Protection and Guidelines on Research Animal Use. The animals were housed in an air-conditioned room at a stable temperature $\left(22-24{ }^{\circ} \mathrm{C}\right)$ and humidity $(45-60 \%)$ on a 12:12 hour light/dark cycle and maintained on a standard pellet diet and tap water ad libitum. Daily water consumption was estimated one week before the experiment and controlled during the treatment.

Adult 12-week-old male Wistar rats were divided into 8 groups with 6 animals in each group: control group (Con), group treated with $40 \mathrm{mg} / \mathrm{kg} /$ day of L-NAME (L); groups receiving L-NAME ( $40 \mathrm{mg} / \mathrm{kg} /$ day) plus indapamide $1 \mathrm{mg} / \mathrm{kg} / \mathrm{day}$ (LI), or captopril $10 \mathrm{mg} / \mathrm{kg} /$ day (LC), or Provinols ${ }^{\mathrm{TM}} 40 \mathrm{mg} / \mathrm{kg} /$ day (LP), or combination of indapamide with captopril (LCI), or combination of indapamide with Provinols ${ }^{\mathrm{TM}}$ (LPI). All compounds were dissolved in the drinking water and administered orally for 7 weeks. At the end of the treatment the body weight (BW) and left ventricular weight (LVW) was measured and LVW to BW ratio was calculated (LVW/BW).

The red wine extract dry powder Provinols ${ }^{\mathrm{TM}}$ was kindly provided by Mr. D. Ageron (Société Francaise de Distillerie, Vallont Pont d'Arc, France). Provinols ${ }^{\mathrm{TM}}$ polyphenols content is known and has been reported (Diebolt et al. 2001) as follows (in $\mathrm{mg} / \mathrm{g}$ of dry powder): proanthocyanidins 480 , total anthocyanins 61 , free anthocyanins 19 , catechin 38 , hydroxycinnamic acid 18 , flavonols 14.

\section{Blood pressure measurement}

The blood pressure (BP) was measured noninvasively by the tail-cuff plethysmography using the Statham Pressure Transducer P23XL (Hugo Sachs, Germany) every week. The final value was calculated from five successive measurements. 


\section{Histology}

The hearts were fixed 24 hours in $10 \%$ formalin, routinely processed in paraffin and $5 \mu \mathrm{m}$ thick sLCIes were stained with hematoxylin and eosin. The slides were evaluated in a Leica light microscope (Leica Systeme, Wetzlar, Germany).

\section{Collagen type I. and III. evaluation}

Sirius red F3BA dissolved in a saturated picric acid stains collagens type I and III, which can be distinguished with the use of polarized light, and their content evaluated by computer assisted morphometry is in concordance with the results obtained by immunohistochemistry and evaluation of mRNA levels (Pauschinger et al. 1999, Allon et al. 2006).

Deparaffinized and rehydrated $5 \mu \mathrm{m}$ thick sLCIes were stained with a modified technique with picrosirius red as follows: the slides were submerged in $0.2 \%$ phosphomolybden acid for clearing the cytoplasm, then the slides were stained with $0.1 \%$ sirius red F3BA in a saturated water solution of picric acid for $90 \mathrm{~min}$. The slides were washed $2 \mathrm{~min}$ in $0.01 \mathrm{~N} \mathrm{HCl}$, dehydrated and mounted.

Five randomly selected places on each slide were selected, viewed under polarized light, documented with a digital photographic camera S50 (Canon, Japan) and evaluated with ImageJ software (National Institute of Health, Bethesda, USA). Threshold values were determined for the particular colors of spectrum, the numbers of pixels of each color were counted and the percentage of the picture's area was calculated.

\section{Statistics}

The results were expressed as mean \pm standard deviation, statistically analyzed by two-way (blood pressure) or one-way ANOVA with Keuls-Neumann test. Values with $\mathrm{p}<0.05$ were considered significant.

\section{Results}

\section{Left ventricular hypertrophy and blood pressure}

Blood pressure of the rats was not significantly different between the groups at the beginning of the experiment. Indapamide and captopril and indapamide together with captopril significantly decreased the blood pressure rise from the second week of treatment when compared with the group receiving L-NAME only. From the fourth week significant decrease of the blood pressure rise was achieved by administration of all tested

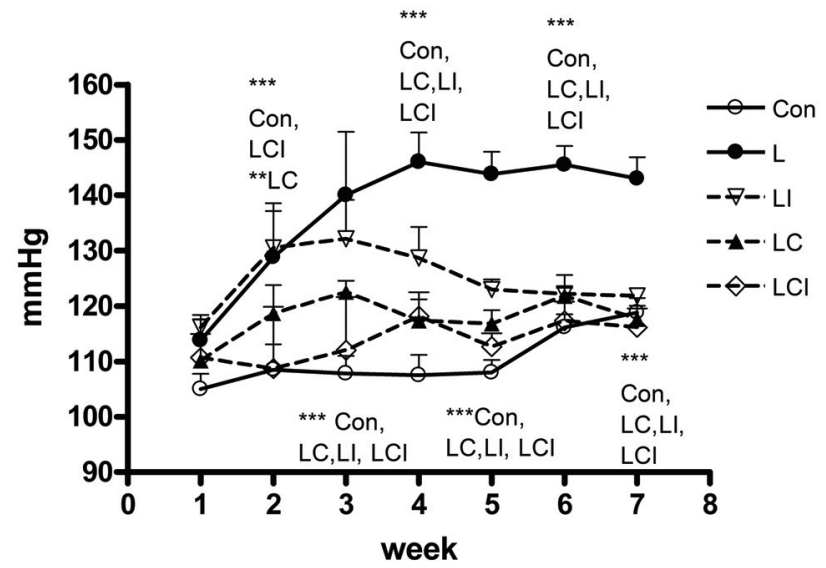

Fig. 1. Blood pressure during simultaneous administration of L-NAME (L) and indapamide (LI), or captopril (LC), or combination of indapamide and captopril (LCI) for 7 weeks. Control is labeled as Con. Numbers represent the average value \pm S.D. ${ }^{*} p<0.05, * * p<0.01, * * * p<0.001$ vs. L-NAME group (L).

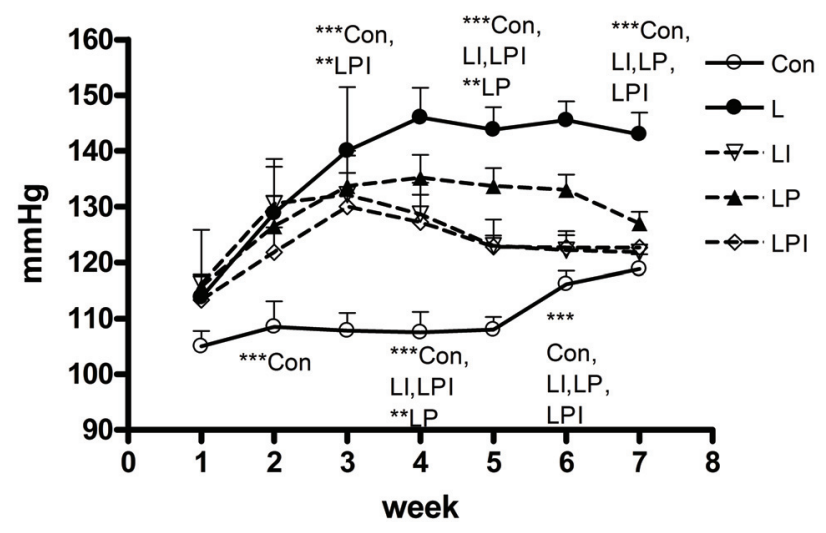

Fig. 2. Blood pressure during simultaneous administration of L-NAME (L) and indapamide (LI), or red wine polyphenols (LP), or combination of indapamide and red wine polyphenols (LPI) for 7 weeks. Control is labeled as Con. Numbers represent the average value \pm S.D. ${ }^{*} \mathrm{p}<0.05,{ }^{* *} \mathrm{p}<0.01, * * * \mathrm{p}<0.001$ vs. L-NAME group (L).

compounds and their combination (Fig. 1 and 2).

The body weight (BW) was not changed in comparison to the control in any of the groups except for the animals receiving captopril and indapamide with a significant decrease of BW. Left ventricular weight and ventricular weight/body weight ratio were increased significantly in rats receiving L-NAME when compared to control; only administration of Provinols ${ }^{\mathrm{TM}}$ caused no significant decrease of these parameters (Table 1).

\section{Myocardial fibrosis}

Changes of myocardial fibrosis can be shown on histological pictures where red to yellow fibers represent collagen type I, green fibers show collagen type III. 
Table 1. Body weight, left ventricular weight and relative left ventricular weight after 7 weeks of administration of N(G)-nitro-L-arginine methyl ester (L-NAME).

\begin{tabular}{lccc}
\hline & $\begin{array}{c}\text { Body weight: } \\
\text { BW (g) }\end{array}$ & $\begin{array}{c}\text { Left ventricular weight: } \\
\text { LVW (mg) }\end{array}$ & $\begin{array}{c}\text { Relative left ventricular weight: } \\
\text { LVW/BW (mg/g) }\end{array}$ \\
\hline Con & $341 \pm 7$ & $465 \pm 29$ & $1.36 \pm 0.07$ \\
$L$ & $349 \pm 10$ & $536 \pm 20^{+}$ & $1.54 \pm 0.06^{+}$ \\
$L I$ & $334 \pm 15$ & $441 \pm 17 *$ & $1.35 \pm 0.08^{*}$ \\
$L C$ & $339 \pm 6$ & $408 \pm 4^{*}$ & $1.21 \pm 0.03 *$ \\
$L C I$ & $305 \pm 16 *$ & $405 \pm 5 *$ & $1.29 \pm 0.5 *$ \\
$L P$ & $352 \pm 13$ & $500 \pm 24$ & $1.43 \pm 0.08$ \\
$L P I$ & $346 \pm 15$ & $420 \pm 5 *$ & $1.23 \pm 0.07 *$ \\
\hline
\end{tabular}

L-NAME (L) and indapamide (LI), or captopril (LC), combination of indapamide and captopril (LCI), or red wine polyphenols (LP), combination of indapamide and red wine polyphenols (LPI). Numbers represent the average value \pm S.D. ${ }^{+} p<0.05$ vs. control (Con), $* \mathrm{p}<0.05$ vs. L.

When digitally processed and statistically evaluated it could be seen that administration of L-NAME resulted in a $73 \%$ increase of collagen type I content in the myocardium when compared to control $(\mathrm{p}<0.001)$. Col I was not reduced by indapamide or captopril in comparison to L-NAME only, but their combination, as well as Provinols ${ }^{\mathrm{TM}}$ with and without indapamide resulted in a significant decrease of relative content of collagen type I in myocardium when compared to the L-NAME group $(\mathrm{p}<0.001$ for all mentioned, data not shown).

Collagen type III was increased by $54 \%$ after administration of L-NAME $(\mathrm{p}<0.05)$ and interestingly, the addition of indapamide caused a further increase of Col III when compared to the control $(\mathrm{p}<0.001$ vs. control), but this change was not significant versus the L-NAME group. No other of the tested substances or combinations caused significant changes in collagen type III in comparison to the control or the L-NAME groups (data shown).

The total myocardial fibrosis increased by $63 \%$ after chronic administration of L-NAME (compared to Con). Neither indapamide nor captopril were able to influence the effect of L-NAME significantly, however, their combination caused a decrease of total fibrosis by $48 \%$. Significant decrease of total fibrosis was observed after simultaneous administration of Provinols ${ }^{\mathrm{TM}}, 42 \%$ without and $53 \%$ with indapamide in comparison to the L-NAME group (Fig. 3).

Collagen type I/III ratio was not changed after chronic administration of L-NAME. All tested compounds added to L-NAME caused a significant decrease of the Col I/III ratio in comparison to both, the control and the

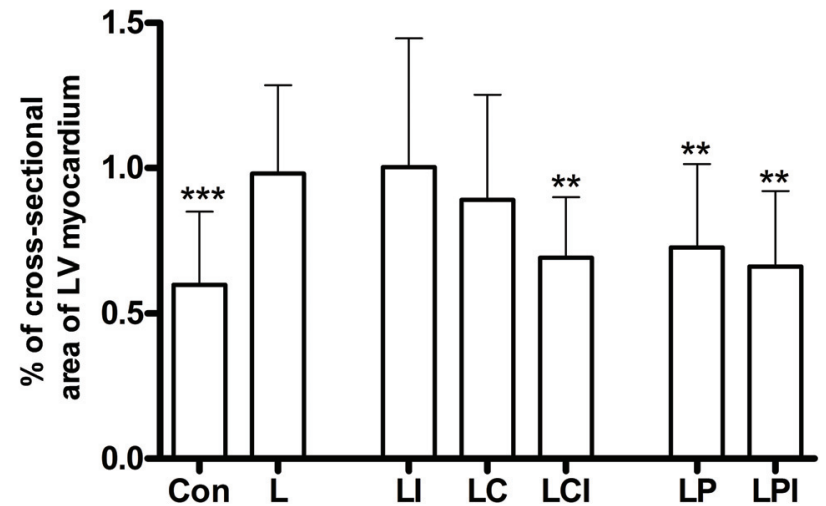

Fig. 3. Myocardial fibrosis after 7 weeks of simultaneous administration of L-NAME (L) and indapamide (LI), or captopril $(\mathrm{LC})$, or combination of indapamide and captopril $(\mathrm{LCI})$, or red wine polyphenols (LP), or combination of indapamide and red wine polyphenols (LPI). Control is labeled as Con. Numbers represent the average value \pm S.D. $* p<0.05, * * p<0.01$, $* * * \mathrm{p}<0.001$ vs. L-NAME group (L).

L-NAME group ( $\mathrm{p}<0.05$ for all groups except Provinols ${ }^{\mathrm{TM}}$ + indapamide where $\mathrm{p}<0.001$; data not shown).

\section{Discussion}

Experimental hypertension produced by chronic administration of L-NAME resulted in increased blood pressure, left ventricular hypertrophy, increased content of Col I, Col III and total fibrosis in the myocardium, but not in the change of Col I/III ratio. Similar effects on blood pressure, left ventricular hypertrophy and total myocardial fibrosis were reported after chronic administration of L-NAME at even lower doses (Pechánová et al. 1999). However, the effect of L-NAME on the two types of collagen and their ratio in the heart 
has not yet been described.

Regarding the process of fibrosis and myocardial hypertrophy the role of both NO and the actual level of blood pressure is still disputable. Comparable changes in the heart can be seen in spontaneously hypertensive rats that have increased production of NO (Janega et al. 2007) and in L-NAME treated rats with NO deficiency. Even administration of L-arginine was not able to prevent the myocardial remodeling in L-NAME treated rats (Simko et al. 2005).

In our study all the investigated substances decreased the blood pressure but their effects on the evaluated parameters in the heart tissue were variable. These results are in concordance with those obtained in L-NAME induced hypertension and in SHR obtained by others (Innes et al. 1998, Kobayashi et al. 2000, Varo et al. 2000), as well as in patients with hypertension (Gottdiener et al. 1997). This suggests the existence of other important factors influencing the heart muscle that are relatively or absolutely independent on NO or on the actual level of blood pressure.

Administration of indapamide alone causes reduction of the blood pressure, regression of the left ventricular hypertrophy and a decrease in the Col I/III ratio, but does not contribute to the decrease of the total fibrosis and relative content of the collagens in L-NAME induced hypertension. These results differ from those obtained in SHR where indapamide reduces the total myocardial fibrosis, but has no effect on the collagen type I/III ratio and its effect was independent on NO synthase activity (Nguyen et al. 1998, Janega et al. 2007).

Myocardial parameters in spontaneously hypertensive rats (Nguyen et al. 1998) after captopril administration were similar to those observed after indapamide treatment. Different results, however, can be seen in SHR and in humans after ACE inhibitor (lisinopril) treatment. While lisinopril causes regression of myocardial fibrosis in SHR, in humans it had no effect on the heart hypertrophy (Serafini et al. 1998).

Surprisingly, combination of captopril and indapamide is able significantly to reduce the total fibrosis and the Col I content. These results indicate that prevention of myocardial fibrosis and hypertrophy seems to be dependent on more than one pathway and that oxidative stress may be one of the contributing factors. Both indapamide and captopril are known to have antioxidant properties (Kojsova et al. 2006), which are probably insufficient to decrease the myocardial fibrosis when administered singly, but are complementary after the combination. The combination of indapamide and captopril was shown to exert additive effects in SHR, increasing NOS activity, eNOS protein expression in the aorta and decreasing conjugated dienes concentration in the kidneys, in contrast with monotherapeutic application (Vranková et al. 2009). As for the body weight loss after the combination of indapamide and captopril, this effect of indapamide or captopril has been reported (Machová 1988, Weisinger et al. 2009). In our experimental settings it was demonstrated that combination of these drugs potentiated their lowering effect on the body weight which was not significant when given individually.

The multifactorial genesis of the myocardial fibrosis and hypertrophy is also supported by the results obtained by the administration of red wine extract Provinols ${ }^{\mathrm{TM}}$. Singly administration of red wine polyphenols is able to decrease the blood pressure in L-NAME induced hypertension, reduces the relative content of the collagen type I together with the total fibrosis and the collagen type I/III ratio. Red wine polyphenols are well known to possess antioxidant properties and enhance plasma antioxidant capacity (Leikert et al. 2002). They also modulate the activity and expression of NO synthases (Diebolt et al. 2001, Kim et al. 2006), influence prostaglandins secretion and cyclooxygenases expression (Oak et al. 2004) and inhibit the synthesis of MMP-2 (Vergely et al. 1998), which is elevated in patients with heart failure (Altieri et al. 2003). Presumably, captopril or indapamide cannot affect all these pathways alone as the red wine polyphenols but they gain these abilities after their combination.

On the other hand, red wine polyphenols alone are not able to influence the LV hypertrophy that obviously develops independently on myocardial fibrosis. But the combination with indapamide provides this additional effect and results in general improvement of the described myocardial parameters.

In conclusion, our results indicate that administration of indapamide is able to prevent the increase of blood pressure and the myocardial hypertrophy but has insignificant effect on myocardial fibrosis. This limitation can be avoided by adding captopril or Provinols ${ }^{\mathrm{TM}}$ to the treatment. Such combinations have the ability to prevent the myocardial fibrosis possibly through various pathways including the enhancement of antioxidant properties and the influence on nitric oxide synthesis. These results may contribute to the ongoing intense search for the optimal antihypertensive therapy schemes with preventive effect on myocardial remodeling. 


\section{Conflict of Interest}

There is no conflict of interest.

\section{Acknowledgements}

The work was supported by the grant APVV-0742-10, VEGA 2/0190/11 and 2/0178/09 and by the Framework
Programme for Research and Technology Development, project: Building of Centre of Excellency for Sudden Cerebral Vascular Events, Comenius University Faculty of Medicine in Bratislava (ITMS: 26240120023), cofinanced by European Regional Development Fund.

\section{References}

ALLON I, VERED M, BUCHNER A, DAYAN D: Stromal differences in salivary gland tumors of a common histopathogenesis but with different biological behavior: a study with picrosirius red and polarizing microscopy. Acta Histochem 108: 259-264, 2006.

ALTIERI P, BRUNELLI C, GARIBALDI S, NICOLINO A, UBALDI S, SPALLAROSSA P, OLIVOTTI L, ROSSETTIN P, BARSOTTI A, GHIGLIOTTI G: Metalloproteinases 2 and 9 are increased in plasma of patients with heart failure. Eur J Clin Invest 33: 648-656, 2003.

ARNAL JF, EL AMRANI AI, CHATELLIER G, MÉNARD J, MICHEL JB: Cardiac weight in hypertension induced by nitric oxide synthase blockade. Hypertension 22: 380-387, 1993.

ARNAL JF, WARIN L, MICHEL JB: Determinants of aortic cycLCI guanosine monophosphate in hypertension induced by chronic inhibition of nitric oxide synthase. J Clin Invest 90: 647-652, 1992.

BARTUNEK J, WEINBERG EO, TAJIMA M, ROHRBACH S, KATZ SE, DOUGLAS PS, LORELL BH: Chronic $\mathrm{N}(\mathrm{G})$-nitro-L-arginine methyl ester-induced hypertension: novel molecular adaptation to systoLCI load in absence of hypertrophy. Circulation 101: 423-429, 2000.

BERNÁTOVÁ I, PECHÁNOVÁ O, BABÁL P, KYSELÁ S, STVRTINA S, ANDRIANTSITOHAINA R: Wine polyphenols improve cardiovascular remodeling and vascular function in NO-deficient hypertension. $A m J$ Physiol Heart Circ Physiol 282: H942-H948, 2002.

BERNÁTOVÁ I, PECHÁNOVÁ O, PELOUCH V, SIMKO F: Regression of chronic L -NAME-treatment-induced left ventricular hypertrophy: effect of captopril. J Mol Cell Cardiol 32: 177-185, 2000.

BERNÁTOVÁ I, PECHÁNOVÁ O, SIMKO F: Captopril prevents NO-deficient hypertension and left ventricular hypertrophy without affecting nitric oxide synthase activity in rats. Physiol Res 45: 311-316, 1996.

CONRAD CH, BROOKS WW, HAYES JA, SEN S, ROBINSON KG, BING OH: Myocardial fibrosis and stiffness with hypertrophy and heart failure in the spontaneously hypertensive rat. Circulation 91: 161-170, 1995.

CONTARD F, GLUKHOVA M, MAROTTE F, NARCISSE G, SCHATZ C, SWYNGHEDAUW B, GUEZ D, SAMUEL JL, RAPPAPORT L: Diuretic effects on cardiac hypertrophy in the stroke prone spontaneously hypertensive rat. Cardiovasc Res 27: 429-434, 1993.

DIEBOLT M, BUCHER B, ANDRIANTSITOHAINA R: Wine polyphenols decrease blood pressure, improve NO vasodilatation, and induce gene expression. Hypertension 38: 159-165, 2001.

GOTTDIENER JS, REDA DJ, MASSIE BM, MATERSON BJ, WILLIAMS DW, ANDERSON RJ: Effect of singledrug therapy on reduction of left ventricular mass in mild to moderate hypertension: comparison of six antihypertensive agents. The Department of Veterans Affairs Cooperative Study Group on Antihypertensive Agents. Circulation 95: 2007-2014, 1997.

HLAVAČKOVÁ L, JANEGA P, CERNÁ A, PECHÁŇOVÁ O, ANDRIANTSITOHAINA R, BABÁL P: Red wine polyphenols affect the collagen composition in the aorta after oxidative damage induced by chronic administration of CC14. Physiol Res 58: 337-344, 2009.

INNES BA, MCLAUGHLIN MG, KAPUSCINSKI MK, JACOB HJ, HARRAP SB: Independent genetic susceptibility to cardiac hypertrophy in inherited hypertension. Hypertension 31: 741-746, 1998.

JANEGA P, KOJSOVÁ S, JENDEKOVÁ L, BABÁL P, PECHÁNOVÁ O: Indapamide-induced prevention of myocardial fibrosis in spontaneous hypertension rats is not nitric oxide-related. Physiol Res 56: 825-828, 2007. 
KIM YA, LIM SY, RHEE SH, PARK KY, KIM CH, CHOI BT, LEE SJ, PARK YM, CHOI YH: Resveratrol inhibits inducible nitric oxide synthase and cyclooxygenase-2 expression in beta-amyloid-treated C6 glioma cells. Int $J$ Mol Med 17: 1069-1075, 2006.

KOBAYASHI N, HARA K, WATANABE S, HIGASHI T, MATSUOKA H: Effect of imidapril on myocardial remodeling in L-NAME-induced hypertensive rats is associated with gene expression of NOS and ACE mRNA. Am J Hypertens 13: 199-207, 2000.

KOJSOVÁ S, JENDEKOVÁ L, ZICHA J, KUNES J, ANDRIANTSITOHAINA R, PECHÁNOVÁ O: The effect of different antioxidants on nitric oxide production in hypertensive rats. Physiol Res 55 (Suppl 1): S3-S16, 2006.

LEIKERT JF, RÄTHEL TR, WOHLFART P, CHEYNIER V, VOLLMAR AM, DIRSCH VM: Red wine polyphenols enhance endothelial nitric oxide synthase expression and subsequent nitric oxide release from endothelial cells. Circulation 106: 1614-1617, 2002.

MACHOVÁ A: The diuretic effect of metipamide and its relationship to body weights in rats. Physiol Bohemoslov 37: 149-158, 1988.

MARIJIANOWSKI MM, TEELING P, MANN J, BECKER AE: Dilated cardiomyopathy is associated with an increase in the type I/type III collagen ratio: a quantitative assessment. J Am Coll Cardiol 25: 1263-1272, 1995.

MORENO H JR, METZE K, BENTO AC, ANTUNES E, ZATZ R, DE NUCCI G: Chronic nitric oxide inhibition as a model of hypertensive heart muscle disease. Basic Res Cardiol 91: 248-255, 1996.

MUKHERJEE D, SEN S: Alteration of cardiac collagen phenotypes in hypertensive hypertrophy: role of blood pressure. J Mol Cell Cardiol 25: 185-196, 1993.

MUKHERJEE D, SEN S: Collagen phenotypes during development and regression of myocardial hypertrophy in spontaneously hypertensive rats. Circ Res 67: 1474-1480, 1990.

NARAYAN S, JANICKI JS, SHROFF SG, PICK R, WEBER KT: Myocardial collagen and mechanics after preventing hypertrophy in hypertensive rats. Am J Hypertens 2: 675-682, 1989.

NGUYEN T, EL SALIBI E, ROULEAU JL: Reduced periinfarction mortality as a result of long-term therapy with captopril but not hydralazine or propranolol in spontaneously hypertensive rats. $J$ Cardiovasc Pharmacol 32: 884-895, 1998.

OAK MH, EL BEDOUI J, ANGLARD P, SCHINI-KERTH VB: Red wine polyphenoLCI compounds strongly inhibit pro-matrix metalloproteinase-2 expression and its activation in response to thrombin via direct inhibition of membrane type 1-matrix metalloproteinase in vascular smooth muscle cells. Circulation 110: 1861-1867, 2004.

PAUSCHINGER M, KNOPF D, PETSCHAUER S, DOERNER A, POLLER W, SCHWIMMBECK PL, KÜHL U, SCHULTHEISS HP: Dilated cardiomyopathy is associated with significant changes in collagen type I/III ratio. Circulation 99: 2750-2756, 1999.

PECHÁNOVÁ O, BERNÁTOVÁ I, BABÁL $\mathrm{P}$, MARTíNEZ MC, KYSELÁ S, STVRTINA S, ANDRIANTSITOHAINA R: Red wine polyphenols prevent cardiovascular alterations in L-NAME-induced hypertension. J Hypertens 22: 1551-1559, 2004.

PECHÁNOVÁ O, BERNÁTOVÁ I, PELOUCH V, BABÁL P: L-NAME-induced protein remodeling and fibrosis in the rat heart. Physiol Res 48: 353-362, 1999.

PECHÁNOVÁ O, BERNÁTOVÁ I, PELOUCH V, SIMKO F: Protein remodelling of the heart in NO-deficient hypertension: the effect of captopril. J Mol Cell Cardiol 29: 3365-3374, 1997.

SERAFINI M, MAIANI G, FERRO-LUZZI A: Alcohol-free red wine enhances plasma antioxidant capacity in humans. J Nutr 128: 1003-1007, 1998.

SCHRAEGER JA, CANBY CA, RONGISH BJ, KAWAI M, TOMANEK RJ: Normal left ventricular diastoLCI compliance after regression of hypertrophy. J Cardiovasc Pharmacol 23: 349-357, 1994.

SIMKO F, LUPTAK I, MATUSKOVA J, KRAJCIROVICOVA K, SUMBALOVA Z, KUCHARSKA J, GVOZDJAKOVA A, SIMKO J, BABAL P, PECHANOVA O, BERNATOVA I: L-arginine fails to protect against myocardial remodelling in L-NAME-induced hypertension. Eur J Clin Invest 35: 362-368, 2005. 
TAKEMOTO M, EGASHIRA K, USUI M, NUMAGUCHI K, TOMITA H, TSUTSUI H, SHIMOKAWA H, SUEISHI $\mathrm{K}$, TAKESHITA A: Important role of tissue angiotensin-converting enzyme activity in the pathogenesis of coronary vascular and myocardial structural changes induced by long-term blockade of nitric oxide synthesis in rats. J Clin Invest 99: 278-287, 1997.

VARO N, IRABURU MJ, VARELA M, LÓPEZ B, ETAYO JC, DÍEZ J: Chronic AT(1) blockade stimulates extracellular collagen type I degradation and reverses myocardial fibrosis in spontaneously hypertensive rats. Hypertension 35: 1197-1202, 2000.

VERGELY C, WALKER MK, ZELLER M, RADEMAKERS JR, MAUPOIL V, SCHIAVI P, GUEZ D, ROCHETTE L: Antioxidant properties of indapamide, 5-OH indapamide and hydrochlorothiazide evaluated by oxygenradical absorbing capacity and electron paramagnetic resonance. Mol Cell Biochem 178: 151-155, 1998.

VRANKOVÁ S, JENDEKOVA L, PAULIS L, SLADKOVA M, SIMKO F, PECHANOVA O: Comparison of the effects of indapamide and captopril on the development of spontaneous hypertension. J Hypertens Suppl 27: S42-S46, 2009.

WEBER KT: Cardiac interstitium in health and disease: the fibrillar collagen network. J Am Coll Cardiol 13: 1637$1652,1989$.

WEI S, CHOW LT, SHUM IO, QIN L, SANDERSON JE: Left and right ventricular collagen type I/III ratios and remodeling post-myocardial infarction. J Card Fail 5: 117-126, 1999.

WEISINGER RS, STANLEY TK, BEGG DP, WEISINGER HS, SPARK KJ, JOIS M: Angiotensin converting enzyme inhibition lowers body weight and improves glucose tolerance in C57BL/6J mice maintained on a high fat diet. Physiol Behav 98: 192-197, 2009.

YAMAMOTO K, MASUYAMA T, SAKATA Y, NISHIKAWA N, MANO T, YOSHIDA J, MIWA T, SUGAWARA M, YAMAGUCHI Y, OOKAWARA T, SUZUKI K, HORI M: Myocardial stiffness is determined by ventricular fibrosis, but not by compensatory or excessive hypertrophy in hypertensive heart. Cardiovasc Res 55: 76-82, 2002.

ZHANG Y, AGNOLETTI D, SAFAR ME, BLACHER J: Effect of antihypertensive agents on blood pressure variability: the Natrilix SR versus candesartan and amlodipine in the reduction of systolic blood pressure in hypertensive patients (X-CELLENT) study. Hypertension 58: 155-160, 2011. 